\title{
MORFOLOGIA DE FRUTOS, SEMENTES, PLÂNTULAS E PLANTAS JOVENS DE Guibourtia hymenifolia (MORIC.) J. LEONARD (FABACEAE) ${ }^{1}$
}

\author{
Joanice Lube Battilani², Etenaldo Felipe Santiago ${ }^{3}$ e Edna Scremin Dias ${ }^{4}$
}

\begin{abstract}
RESUMO - Guibourtia hymenifolia (Moric.) J. Leonard (Fabaceae) é uma espécie arbórea de potencial madeireiro com ocorrência natural nas florestas estacionais deciduais e semideciduais sob afloramentos calcários na Serra da Bodoquena, Mato Grosso do Sul, Brasil. Foram descritos e ilustrados os aspectos morfológicos dos frutos, sementes e desenvolvimento das plântulas e plantas jovens de G. hymenifolia. O fruto é do tipo legume, deiscente, unispermo. A semente possui forma elíptica, forte coloração alaranjada e presença de arilo esbranquiçado de origem funicular. Obtiveram-se $66 \%$ de germinação em câmara de germinação, sendo a morfologia inicial das plântulas fanerocotiledonar epígea, com cotilédones carnosos. As plântulas e plantas jovens apresentam mudança de filotaxia, sendo os eofilos opostos e unifoliolados e os metafilos, alternos, peciolados e bifoliolados. Eofilos e metafilos apresentam nervação pinada do tipo camptódromo broquidódromo. Esses resultados contribuem em estudos taxonômicos da espécie e permitem a identificação das plântulas em estudos de regeneração natural.
\end{abstract}

Palavras-chave: Regeneração natural, Germinação e Nervação foliar.

\section{MORPHOLOGY OF FRUITS, SEEDS, SEEDLING AND SAPLING OF Guibourtia hymenifolia (MORIC.) J. LEONARD (FABACEAE)}

\begin{abstract}
Guibourtia hymenifolia (Moric.) J. Leonard (Fabaceae) is a timber great potential tree species, with occurrence in seasonal deciduous and semideciduous forests in Serra da Bodoquena, Mato Grosso do Sul, Brazil. It was described and illustrated in this paper, the morphological aspects of fruit, seeds and development of seedlings and saplings of $\mathbf{G}$. hymenifolia. The fruit is a dehiscent unyspermic legume. The seed is elliptic, orange colored with the presence of whitish funiculus aril. It was obtained $66 \%$ of germination in a germination chamber, and the initial morphology of the seedlings was epigeos phanerocotyledonary, with fleshy cotyledons. Seedlings and saplings presented changing of phylotaxis, with two opposite and alternate, petiolate and bifoliolate metaphylls. Eophylls and metaphylls present pinnate, camptodromous, brochidodromous venation pattern. These results can be used to identify the species in taxonomic studies and they allow the identification of seedlings in natural regeneration studies.
\end{abstract}

Keywords: Natural regenaration, Germination and Venation pattern.

\section{INTRODUÇÃO}

Guibourtia hymenifolia (Moric.) J. Leonard (Fabaceae), sinonímia G. chodatiana (Hassl.) J. Leonard (JARDIM et al., 2003), é uma espécie arbórea de grande porte, podendo atingir até $30 \mathrm{~m}$ de altura e diâmetro entre 40 e $70 \mathrm{~cm}$. É conhecida popularmente por jatobámirim, copaibeira (LORENZI, 1998) e sirari nas florestas secas da Bolívia e Paraguai (JARDIM et al., 2003). No Brasil, ocorre naturalmente nos estados da Região Nordeste, na Caatinga arbórea e no Pantanal MatoGrossense, na mata Chaquenha. Apresenta distribuição exclusiva em Florestas Estacionais Decíduas e Semidecíduas sob solos ricos com afloramentos de rochas calcárias (LORENZI, 1998). É classificada como

\footnotetext{
${ }^{1}$ Recebido em 02.07.2009 e aceito para publicação em 02.05.2011.

${ }^{2}$ Instituto Brasileiro do Meio Ambiente, IBAMA, Brasil. E-mail: <joanicebattilani@gmail.com>.

${ }^{3}$ Universidade Estadual de Mato Grosso do Sul, UEMS, Brasil. E-mail: <felipe@uems.br>

${ }^{4}$ Universidade Federal de Mato Grosso do Sul, Brasil. E-mail: <scremin@nin.ufms>.
} 
semidecídua, clímax exigente de luz, considerada de elevado potencial madeireiro (LORENZI, 1998; JARDIM et al., 2003) e de extrema importância ecológica pela presença de frutos amplamente consumidos por vertebrados (WALLACE et al., 2000; REYS et al., 2005).

No Estado de Mato Grosso do Sul, G. hymenifolia é também denominada Pseudocopaiva chodatiana (Hassl.) Dwyer (POTT; POTT, 2003) e apresenta distribuição ao longo das florestas ripárias em solos calcários na região da Serra da Bodoquena (BATTILANI et al., 2005; REYS et al., 2005), em Florestas Estacionais Decíduas na Serra de Maracaju (TAKAHASHI; FIANA, 2004) e na morraria calcária em Corumbá (DAMASCENO JÚNIOR, 2005). Essas regiões, caracterizadas pela presença de solos calcários, são fortemente influenciadas pela vegetação chaquenha, apresentando em sua composição florística tanto espécies do Chaco quanto da Caatinga (POTT; POTT, 2003).

São escassas na literatura referências ao gênero Guibourtia J. J. Bennett. Segundo Barneby (1996), existem registros de cinco espécies de Guibourtia com distribuição neotropical. Entretanto, esse autor considerou tratar-se da mesma espécie, inferindo que há somente uma espécie de Guibourtia na América, com distribuição altamente descontínua nas florestas estacionais secas de Cuba, Regiões Nordeste e Oeste do Brasil e Oeste do Paraguai, sendo G. hymenaeifolia a espécie comum entre essas regiões. No entanto, Veiga Júnior e Pinto (2002) descreveram que esse gênero, na África Ocidental, tem sinonímia no gênero Copaifera L., sendo citada a ocorrência das espécies $C$. hymenaeifolia e C. chodatiana naquele continente.

Descrições sobre a morfologia dos frutos e sementes de G. hymenifolia são encontradas em Lorenzi (1998) e Jardim et al. (2003); no entanto, não existem estudos sobre a caracterização morfológica das plântulas e plantas jovens dessa espécie. Porém, são comuns estudos dessa natureza sobre C. langsdorffii Desf. (CRESTANA; BELTRATI, 1988; OLIVEIRA, 1997; GUERRAet al., 2006) e espécies comumente conhecidas por jatobás, do gênero Hymenaea L. (OLIVEIRA, 1997; BOTELHO et al., 2000; CRUZ et al., 2001; MELO et al., 2004; KODAMA; SARTORI, 2007).

Estudos morfológicos de frutos, sementes e desenvolvimento de plântulas e plantas jovens são frequentes para diversas espécies de leguminosas. Em geral são realizados com propósitos taxonômicos, filogenéticos (SANTIAGO; PAOLI, 1999; OLIVEIRA, 2001; SILVA; MÔRO, 2008) e ecológicos, visando auxiliar a classificação das espécies quanto à forma de dispersão, categoria sucessional e identificação das formas juvenis em estudos de regeneração natural (FERREIRA et al., 2001; CUNHA; FERREIRA, 2003; MELO; VARELA, 2006; AMORIM et al., 2008; MILANEZ et al., 2008; RAMOS; FERRAZ, 2008). A biometria de frutos e sementes, bem como o conhecimento da morfologia e desenvolvimento das plântulas, é fundamental para subsidiar estudos de germinação e produção de mudas para recomposição vegetal (LEONHARDT et al., 2008).

O padrão de nervação foliar tem sido estudado como subsídio para identificação de espécies (CARDOSO; SAJO, 2004) ou para comparações entre espécies do mesmo gênero (PAOLI et al., 1995; BATTILANI et al., 2006, 2007). Nesse sentido, a nervação das folhas jovens é importante ferramenta para comparações morfológicas e identificação das plântulas em ambiente natural.

São crescentes a pressão antrópica e fragmentação das formações florestais no Estado de Mato Grosso do Sul, colocando em risco a manutenção de populações de diversas espécies arbóreas com distribuição restrita a essas formações (POTT; POTT, 2003). Apesar de $G$. hymenifolia ter distribuição restrita a florestas estacionais decíduas e semidecíduas em algumas regiões do Brasil (LORENZI, 1998), verificou-se que são insuficientes informações taxonômicas, biológicas e ecológicas referentes a essa espécie (LORENZI, 1998; JARDIM et al., 2003). Estudos dessa natureza são de extrema importância, visando à conservação e preservação das áreas de ocorrência natural, bem como à utilização de $G$. hymenifolia em projetos silviculturais ou de recomposição vegetal.

Nesse contexto, este estudo descreve os aspectos morfológicos dos frutos, sementes, plântulas e plantas jovens e analisa o padrão de nervação das folhas de G. hymenifolia, com o propósito de contribuir para o conhecimento biológico da espécie, identificação das formas juvenis em ambiente natural e fornecer informações para utilização da espécie em programas de reflorestamento e recuperação de áreas degradadas.

\section{MATERIAL E MÉTODOS}

Os frutos e sementes de Guibourtia hymenifolia foram coletados diretamente de 10 árvores-matriz, com o auxílio de podão de 10 m, e no chão, embaixo das 
árvores, no período de agosto a outubro de 2000, em um trecho da floresta ripária do rio da Prata, Município de Jardim, MS, Brasil ( $21^{\circ} 24^{\prime}$ S e $56^{\circ} 21^{\prime}$ W). O material foi triado e examinado no Laboratório de Biologia Vegetal da Universidade Estadual de Mato Grosso do Sul, Unidade de Ensino de Jardim, MS. Exsicatas da espécie foram depositadas (Rg. no 12941/13164) no Herbário (CGMS) da Universidade Federal de Mato Grosso do Sul, Campo Grande (BATTILANI et al., 2005). O processo de beneficiamento foi manual, sendo consideradas somente sementes não predadas, que foram selecionadas e armazenadas em sacos de papel em temperatura ambiente.

A análise morfométrica foi realizada no final das coletas, em amostras aleatórias de 30 unidades para frutos e 100 unidades para sementes. As dimensões, comprimento (mm), largura ( $\mathrm{mm}$ ) e massa (g) foram verificadas com o auxílio de paquímetro digital (Starret) (precisão de 0,01 mm) e balança analítica (Micronal B600) (precisão de 0,01 g). Nas observações e ilustrações dos frutos e sementes foi utilizado estereomicroscópio (Ziess Stemi SV6) provido de câmara clara, e a terminologia adotada na descrição foi a seguida por Barroso et al. (1999) e Corner (1976).

Para os estudos pós-seminais foi retirado o arilo das sementes, sendo estas desinfectadas em hipoclorito de sódio 5\% (durante $30 \mathrm{~min}$ ) e em seguida lavadas em água corrente. Dez amostras de 10 sementes cada foram colocadas para germinar em novembro de 2000, sem tratamento pré-germinativo, em placas de Petri, forradas com duas folhas de papel-filtro e umedecidas com cerca de $1 \mathrm{ml}$ de água destilada em Câmara de Germinação, tipo BOD, a $25^{\circ} \mathrm{C}$ sob luz fluorescente branca contínua. Conjuntamente, com o objetivo de complementar as observações obtidas em câmara de germinação, 30 sementes, sem o arilo, foram submetidas à germinação, sem tratamento pré-germinativo, em tubetes de polietileno contendo substrato agrícola Plantmax, em viveiro com cobertura sombrite $50 \%$, em condições ambientais, e irrigação diária por microaspersão.

Foram realizadas observações diárias, durante o período de 60 dias, anotando-se a data do teste e do início da germinação (determinado pela emergência da raiz primária), bem como o desenvolvimento das plântulas e plantas jovens. Foram descritos o tipo de morfologia inicial da plântula, o desenvolvimento da raiz, o hipocótilo e epicótilo, o tipo e morfologia dos cotilédones, eofilos e metafilos. Foi considerada como plântula a fase inicial do desenvolvimento pós-seminal, desde a emissão da raiz primária até a completa liberação e expansão do primeiro par de eofilos e planta jovem e as fases sucessivas com surgimento dos metafilos.

O padrão de nervação das folhas do primeiro par de eofilos e metafilos foi analisado segundo técnicas de clarificação e coloração baseadas em Handro (1967) e montadas entre placas de vidro. A descrição e classificação dos padrões de nervação seguiram os tipos básicos definidos por Hickey (1979). A terminologia adotada na descrição das plântulas e plantas jovens seguiu Oliveira (1997; 2001). Nas observações e ilustrações do padrão de nervação e das fases iniciais do desenvolvimento das plântulas foi utilizado estereomicroscópio (Ziess Stemi SV6), provido de câmara clara, e para as plantas jovens as ilustrações foram elaboradas a olho nu, em escalas correspondentes.

\section{RESULTADOS}

Guibourtia hymenifolia possui fruto do tipo legume, unispermo, estipitado, linear oblongo, ápice acuminado, coriáceo, de coloração marrom quando maduro (Figura 1A). É seco, com deiscência lateral, que ao abrir expõe a semente que permanece ligada pelo funículo, na região apical (Figura 1B). Os frutos possuem de 14,9 a 25,3 mm de comprimento (19,42 $\pm 2,47), 11,5$ a 22,2 mm de largura $(12,94 \pm 1,06)$ e pesam entre 0,31 e $0,95 \mathrm{~g}(0,57 \pm 0,13)$ (Tabela 1).

A semente madura (Figura 1CD) é ligeiramente elíptica, apresenta testa lisa, brilhante, de forte coloração alaranjada, arilo funicular, esponjoso, esbranquiçado, que recobre o hilo e a micrópila. O hilo é ventral, pequeno de forma elíptica, a micrópila é apical e circular e a rafe é ventral (Figura 1E). As sementes medem de 9,8 a 15,0 mm de comprimento (12,09 $\pm 1,12), 6,0$ a 10,0 mm de largura $(8,05 \pm 0,74)$ e pesam aproximadamente 0,27 a $0,63 \mathrm{~g}(0,41 \pm 0,07)$ (Tabela 1$)$.

Obtiveram-se 66\% de germinação em câmara de germinação e 73\% em viveiro de mudas. A morfologia inicial da plântula é fanerocotiledonar epígea e após a germinação o hipocótilo desenvolve-se, elevando os cotilédones carnosos sobre o solo. A embebição das sementes ocorreu a partir do $3^{\circ}$ dia e o início do rompimento do tegumento, no $5^{\circ}$ dia, com emissão da raiz primária (Figura $2 \mathrm{AB}$ ). No $7^{\circ}$ dia, a raiz primária apresentava coloração esbranquiçada, glabra e o hipocótilo, coloração avermelhada, piloso (Figura 2C). 
No $10^{\circ}$ dia, tiveram início a liberação dos cotilédones e o surgimento de raízes secundárias (Figura 2D). Em tubetes, por volta do $15^{\circ}$ dia, ocorreu a completa liberação dos cotilédones (Figura 2E). A plântula no $15^{\circ}$ dia apresenta raiz primária espessa, presença de raízes secundárias, hipocótilo avermelhado, piloso, cotilédones carnosos ligeiramente elípticos e esbranquiçados. Aos

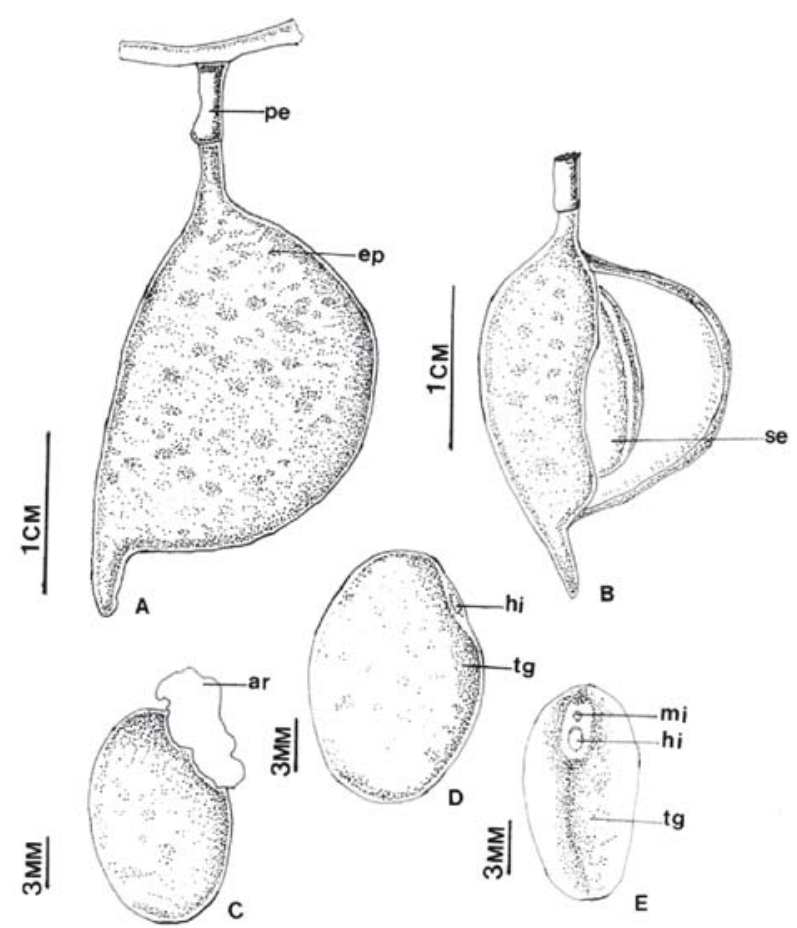

Figura 1 - Morfologia do fruto e da semente de G. hymenifolia (Moric.) J. Leonard. A: Aspecto externo do fruto fechado. B: Fruto aberto. C: Semente com arilo funicular. D e E: Semente (ar: arilo, hi: hilo, mi: micrópila, pe: pedúnculo, se: semente, tg: tegumento).

Figure 1 - Fruit and seed morphology of G hymenifolia (Moric.) J. Leonard. A. External aspect of closed fruit. B. Opened fruit. C. Seed with funiculus aril. D and E. Seed. $(a r=$ aril; hi $=$ hilum; $m i=$ micropyle $; p e=$ peduncle; se= seed; $t$ = tegument).

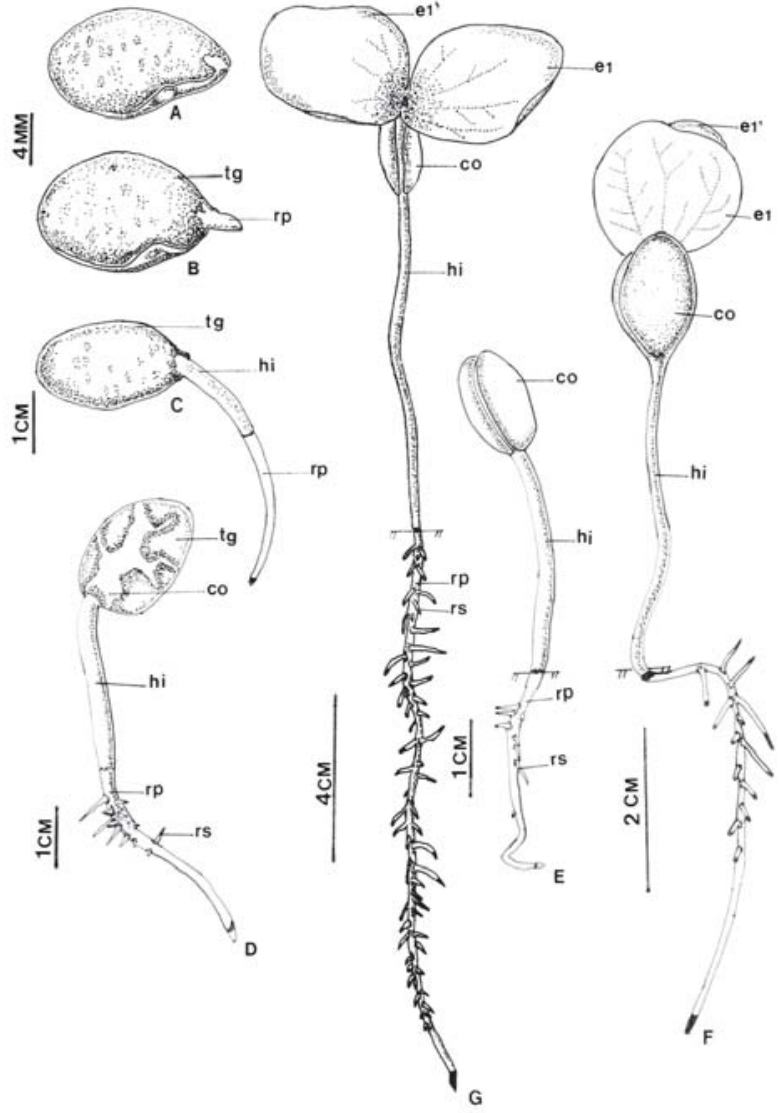

Figura 2 - Estádios de desenvolvimento da plântula de $G$. hymenifolia (Moric.) J. Leonard. A: Com três dias. B: Com cinco dias. C: Com sete dias. D: Com 10 dias. E: Com 15 dias. F: Com 20 dias. G: Com 30 dias (ct: cotilédone, ep: epicótilo, e1 e e1’: eofilos, hi: hilo, hi: hipocótilo, rp: raiz primária, rs: raiz secundária e tg: tegumento).

Figure 2-Development stages of seedling stages $\mathbf{G}$ hymenifolia (Moric.) J. Leonard. A: At three days of age. B: At five days of age. $C$ : At seven days of age. $D$ : At 10 days of age. E: At 15 days of age. F: At 20 days of age. $G$ : At 30 days of age (ct = cotyledon; ep = epicotyl; $e 1$ and $e 1^{\prime}=$ pair of eophylls; hi $=$ hilum; hi = hypocotyls; $r p=$ primary root; $r s=$ secondary root and $t g=$ tegument $)$.

Tabela 1 - Morfometria de frutos $(\mathrm{N}=30)$ e sementes $(\mathrm{N}=100)$ de Guibourtia hymenifolia (Moric.) J. Leonard. Table 1 - Morphometry of fresh fruit $(N=30)$ and seeds $(N=100)$ of Guibourtia hymenifolia (Moric.) J. Leonard.

\begin{tabular}{lcccccc}
\hline & & \multicolumn{2}{c}{ Frutos } & & \multicolumn{2}{c}{ Sementes } \\
\hline Variáveis & Média & Desvio- padrão & Amplitude de variação & Média & Desvio-padrão & Amplitude de variação \\
Comprimento $(\mathrm{mm})$ & 19,82 & 2,47 & $14,92-25,29$ & 12,09 & 1,12 & $9,87-15,02$ \\
Largura (mm) & 12,94 & 1,06 & $11,53-15,14$ & 8,05 & 0,74 & $5,99-10,24$ \\
Peso (g) & 0,57 & 0,13 & $0,31-0,95$ & 0,41 & 0,07 & $0,27-0,62$ \\
\hline
\end{tabular}

Revista Árvore, Viçosa-MG, v.35, n.5, p.1089-1098, 2011 
20 dias, teve início o desenvolvimento do $1^{\circ}$ par de eofilos, de coloração verde, membranáceos com nervação aparente (Figura 2F). Aos 30 dias, o epicótilo alongou-se e delineou o $1^{\circ}$ par de eofilos, opostos, sésseis, suborbiculares com base assimétrica (Figura 2G). A senescência cotiledonar teve início aos 30 dias, e a abscisão ocorreu por volta de 60 dias. Aos 45 dias ocorre o desenvolvimento de raízes terciárias e a planta jovem apresenta o $1^{\circ}$ metafilo (Figura 3A). Aos 90 dias (Figura 3B), a planta jovem apresenta sistema radicular axial, com raízes secundárias e terciárias, hipocótilo de coloração marrom, epicótilo verde, meristema apical e folhas jovens de coloração avermelhada. Na planta
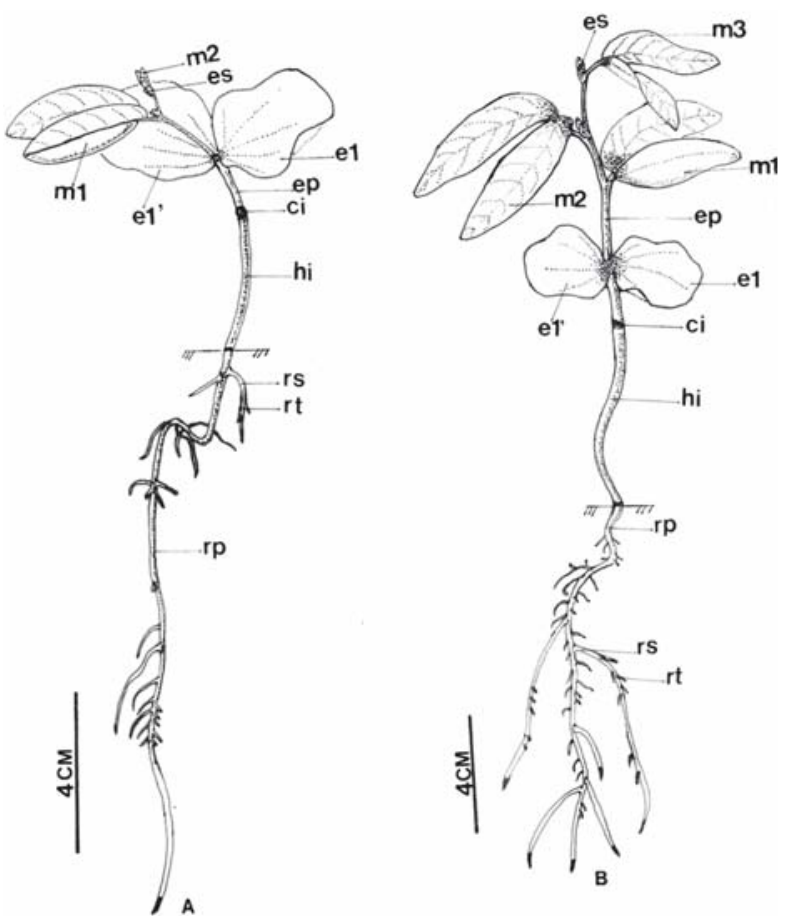

Figura 3 - Planta jovem de G. hymenifolia (Moric.) J. Leonard. A: Com 45 dias. B: Com 75 dias (ci: cicatriz cotiledonar, co: cotilédone, ep: epicótilo, es: estípula, e1 e e1': eofilos, hi: hipocótilo, m1: primeiro metafilo, m2: segundo metafilo, m3: terceiro metafilo, rp: raiz primária, rs: raiz secundária e rt: raiz terciária).

Figure 3 - Sapling of G. hymenifolia (Moric.) J. Leonard. A: At 45 days. B: At 75 days. (ci: cotyledon, co: cotyledon; ep: epycotyl; es: exstipule, e1 e e1': pair of eophylls; hi: hypocotyls, m1: metaphyll first, m2: metaphyll second, m3: metaphyll third, rp: primary root, rs: secundary root and rt: terciary root). jovem, os metafilos apresentam-se alternos, bifoliolados, com dois folíolos assimétricos de ápice agudo, concrescentes na base, peciolados, com estípulas caducas na base do pecíolo.

As plântulas de G. hymenifolia apresentam eofilos simples, sésseis, opostos, com lâmina foliar simétrica, glabra de forma suborbicular, ápice e base arredondada, margem inteira e textura levemente coriácea (Figura 4A).

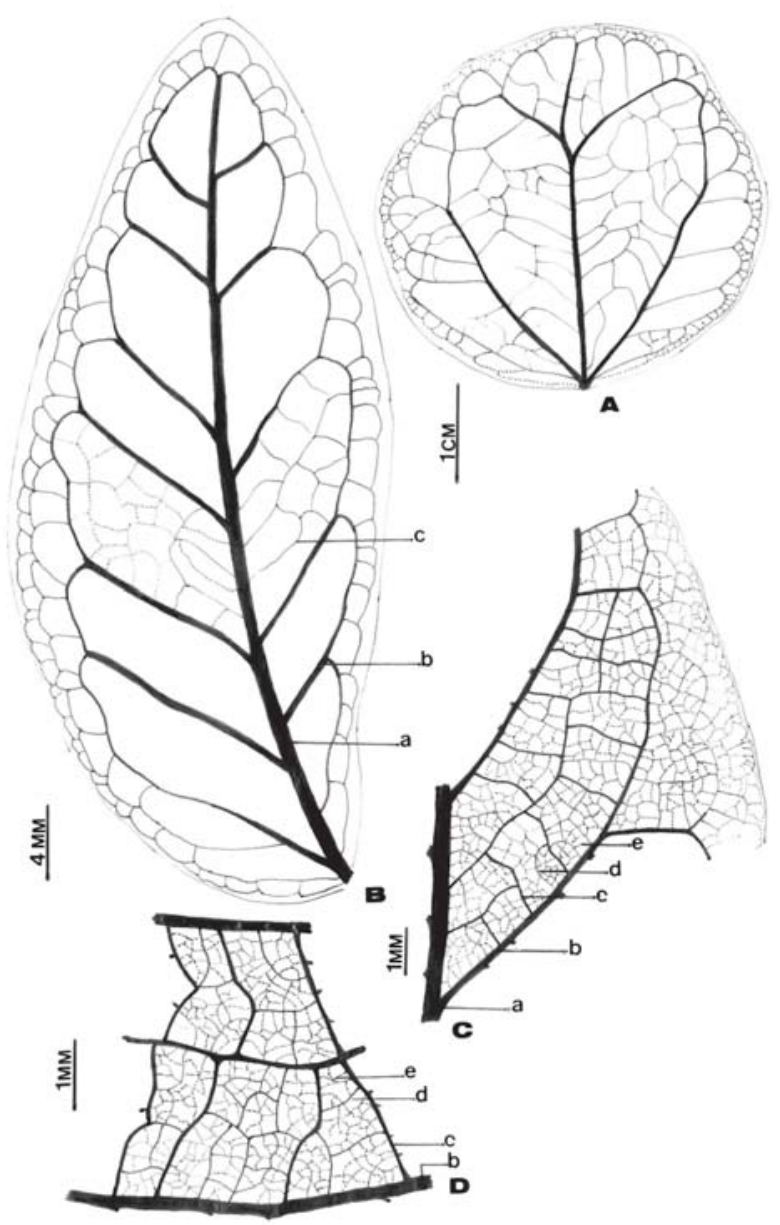

Figura 4 - Padrão de nervação de G. hymenifolia (Moric.) J. Leonard. A: Eofilo. B: Metafilo. C e D: Padrão geral de nervação do metafilo (a: nervura primária, b: nerv. secundária, c: nerv. terciária, d: nerv. quaternária e: nerv. quinquenária).

Figure 4 - Venation pattern of G. hymenifolia (Moric.) $\mathrm{J}$. Leonard. $A=$ Eophyll; $B=$ Metaphyll; $C$ and $D=$ General view of venation pattern $(a=$ primary venation, $b=$ secundary venation, $c=$ terciary venation, $d=$ quartenary venation and $e=$ quinquenary venation). 
A nervação dos eofilos é do tipo pinada com padrão camptódromo broquidódromo com nervura primária evidente que se estende a partir de um ponto basal (Figura 4A). As nervuras laterais apresentam desenvolvimento perfeito, reticulado curvo. O metafilo (Figura 4B) é bifoliolado composto por folíolos assimétricos côncavo-convexos, glabros de forma elíptica, com ápice agudo, base cordada aguda e margem inteira. A textura é levemente membranácea, e o pecíolo é normal. A nervação é do tipo pinada com padrão camptódromo broquidódromo (Figura 4B). As nervuras primárias não terminam na margem, e as secundárias se juntam e formam proeminentes arcos paralelos à margem. A nervura primária é forte (3,7\%) e de curso reto não ramificado. Nas nervuras secundárias, o ângulo de divergência é agudo moderado e uniforme em toda a lâmina (Figura 4C). A espessura é moderada e o curso, curvado do tipo abrupto. As terminações das nervuras secundárias nas margens formam ângulos variáveis: agudos, retos e obtusos. As nervuras intersecundárias são do tipo composta. O padrão das nervuras de terceira ordem é do tipo casualmente reticulado de curso forquilhado, oblíquas em relação à nervura primária, organização predominantemente alternada (Figura 4D). A nervação superior é distinta. As nervuras quaternárias e quinquenárias são relativamente densas, com curso casualmente orientado. A nervação marginal é em laçadas. As vênulas são ramificadas (1 vez) e as aréolas bem desenvolvidas, com arranjo casual e forma irregular (Figura 4D).

\section{DISCUSSÃO}

Os resultados evidenciaram que os frutos de $G$. hymenifolia apresentam morfologia semelhante à dos frutos de Copaifera langsdorffii (CRESTANA; BELTRATI, 1988). No entanto, apesar de as sementes dessas espécies apresentarem dimensões semelhantes, diferenciam-se quanto à forma e coloração. G. hymenifolia possui sementes de coloração alaranjada e arilo esbranquiçado, ao contrário de C. langsdorffii, que possui sementes de coloração negra brilhante e arilo de coloração amarelo-alaranjado (GUERRA et al., 2006). As semelhanças morfológicas dos frutos dos gêneros Copaifera e Guibourtia concordam com afirmações de Lorenzi (1998) e Jardim et al. (2003), que citaram as espécies $C$. hymenifolia e $C$. chodatiana, respectivamente, como sinonímias para G. hymenifolia. No entanto, a morfologia dos frutos e sementes de
G. hymenifolia difere das espécies do gênero Hymenaea que apresentam frutos grandes, com pericarpo seco, indeiscente, lenhoso, com polpa farinácea envolvendo sementes grandes com mais de uma por fruto (OLIVEIRA, 1997; CRUZ et al., 2001; MELO et al., 2004). Dessa forma, apesar de $G$. hymenifolia ser conhecida popularmente como jatobá-mirim, não existem semelhanças entre a morfologia dos frutos e sementes entre os gêneros Guibourtia e Hymenaea.

As dimensões obtidas para as sementes de $G$. hymenifolia permitem inferir para a espécie sementes de tamanho médio e lotes homogêneos, indicando ser uma espécie com potencial para produções de mudas nativas e utilização em programas de reflorestamento florestal. A forte coloração alaranjada das sementes, logo após a dispersão, e a presença de arilo funicular esbranquiçado contribuem para a diferenciação da espécie dentro da família e estão diretamente relacionadas com a zoocoria (HOWE; SMALLWOD, 1982; BARROSO et al., 1999). Crestana e Beltrati (1988) descreveram que a presença de arilo funicular de coloração amareloviva, contrastando com a testa negra e brilhante em sementes de $C$. langsdorfii, favorece a dispersão zoocórica. Essas autoras definiram arilo como excrescência carnosa, anular que se desenvolve do funículo. Entretanto, o arilo presente em sementes de G. hymenifolia também pode ser considerado elaiossoma, termo ecológico utilizado para designar partes carnosas em sementes comestíveis, ricas em nutrientes, de coloração amarela ou branca, amplamente dispersas por formigas (ROTH, 1977).

Esses resultados sugerem para as sementes da espécie uma dispersão primária a curta distância, pela deiscência dos frutos, e dispersão secundária mirmecórica. Segundo Reys et al. (2005), a época de dispersão das sementes de G. hymenifolia está associada ao final da estação seca e início do período chuvoso, ressaltando-se a importância ecológica dessa espécie nas florestas ripárias na região Sudoeste do Estado de Mato Grosso do Sul. No entanto, são necessários estudos complementares, a fim de avaliar os períodos de floração e frutificação e a forma de dispersão das sementes dessa espécie, uma vez que essas informações, aliadas às características morfológicas e biométricas dos frutos e sementes, colaboram em programas de colheita de sementes, visando à produção de mudas de espécies florestais nativas (PIÑA-RODRIGUES, 2002; ALBRECHT et al., 2003). 
A morfologia inicial verificada nas plântulas de G. hymenifolia, do tipo epígea carnosa, é semelhante à das plântulas de espécies do gênero Hymenaea L. (OLIVEIRA, 1997; MELO et al., 2004; RESSEL et al., 2004; KODAMA; SARTORI, 2007) e de Copaifera langsdorffii (GUERRA et al., 2006). Germinação do tipo epígea carnosa foi observada em plântulas de Erythrina speciosa Andrews (OLIVEIRA, 2001), sendo descrita por Ibarra Manríquiz et al. (2001) como o tipo de germinação mais frequente em Fabaceae. No entanto, Ressel et al. (2004) observaram grande variação no tipo de germinação de espécies de leguminosas, apresentando plântulas fanerocotiledonares epígeas e hipógeas como criptocodiledonares hipógeas. A presença de estípulas foliáceas caducas na base do pecíolo é citada para $C$. langsdorffii e $H$. courbaril (JARDIM et al., 2003). Porém, Guerra et al. (2006) e Melo et al. (2004) não descreveram a presença dessas estruturas em plântulas de C. langsdorfii e H. intermedia Ducke, respectivamente. No entanto, Oliveira (2001), Milanez et al. (2008) e Ramos e Ferraz (2008) citaram a presença de estípulas em plântulas de leguminosas como E. speciosa, Pachyrhizus ahipa (Wedd.) Paradi e Enterolobium schomburgkii Benth., respectivamente. Dessa forma, a presença dessas estruturas torna-se relevante em estudos taxonômicos e filogenéticos para espécies de leguminosas.

A função e posição dos cotilédones é a principal característica para a classificação morfológica das plântulas. Espécies tolerantes à sombra que germinam em condições de sub-bosque de florestas primárias frequentemente possuem sementes com grande quantidade de reservas e plântulas com cotilédones carnosos, aumentando a probabilidade de sobrevivência sob condições limitadas de luz. Ao contrário de espécies de florestas secundárias que possuem sementes com poucas reservas e plântulas com cotilédones fotossintetizantes, possibilitando a germinação e rápido crescimento em condições de alta luminosidade (IBARRA MANRÍQUEZ et al., 2001).

As características morfológicas iniciais das plântulas de G. hymenifolia corroboram a classificação ecológica da espécie como clímax exigente de luz (LORENZI, 1998), entretanto sugerem para a espécie condições de germinação e permanência no sub-bosque em condições de baixa luminosidade. Conquanto são necessários estudos de germinação das sementes em diferentes temperaturas e luminosidade, bem como o desenvolvimento das plantas em diferentes condições de sombreamento, visando avaliar as características ecológicas da espécie. O percentual de germinação obtido para $G$. hymenifolia mostra que as sementes recém-colhidas de $G$. hymenifolia possuem tegumento permeável de fácil embebição. A impermeabilidade do tegumento à água é o mecanismo de dormência mais comum em sementes de leguminosas tropicais (CORNER, 1976). Oliveira et al. (2008) obtiveram maior porcentagem de germinação em sementes de Dimorphandra mollis Benth. submetidas à escarificação mecânica em relação às escarificações química e térmica, indicando a presença de dormência tegumentar nas sementes dessa espécie. No entanto, esses autores não fizeram referência ao tempo e condições de armazenamento das sementes utilizadas, sendo essas informações de fundamental importância na interpretação dos resultados, uma vez que o tempo de armazenamento aumenta a impermeabilidade do tegumento das sementes. Em condições de laboratório, variações de temperatura podem influenciar diretamente no processo germinativo. Rosseto et al. (2009) verificaram que temperaturas de 25,30 e $35^{\circ} \mathrm{C}$ aceleram e uniformizam o processo germinativo de sementes de Parkia pendula (Willd.) Benth. ex Walp. (Fabaceae), aumentando a porcentagem de plântulas normais. Dessa forma, são relevantes estudos complementares sobre $G$. hymenifolia, avaliando a taxa germinativa sob diversas condições de armazenamento, temperatura e escarificação mecânica ou química, a fim de determinar a existência de dormência nas sementes, além de acelerar e uniformizar o processo germinativo.

A mudança de filotaxia observada em $G$. hymenifolia com presença do primeiro par de eofilos sésseis de forma suborbicular seguida de metafilos bifoliolados, de posição alterna, com folíolos assimétricos, peciolados é uma característica comum do gênero Hymenaea (MELO et al., 2004). A presença de eofilos opostos seguidos de metafilos alternos também foi observada em plântulas de Erythrina speciosa (OLIVEIRA, 2001) e P. ahipa (MILANEZ et al., 2008), sendo descrita como característica comum de diversas espécies de leguminosas. As semelhanças das características morfológicas dos eofilos e metafilos das plântulas e plantas jovens de $G$. hymenifolia e $H$. courbaril L. justificam a denominação comum dessas espécies, como jatobá-mirim. No entanto, a presença de folhas bifolioladas no gênero Guibourtia e unifolioladas no gênero Copaifera é a principal 
característica que diferencia as espécies desses gêneros (BERNEBY, 1996). Conforme informaram Guerra et al. (2006), plântulas e plantas jovens de C. langsdorfii não apresentaram eofilos, somente metafilos compostos, paripinados, com dois a três pares de folíolos.

O padrão de nervação encontrado nas folhas jovens de $G$. hymenifolia é semelhante ao descrito a respeito de folhas maduras de $H$. courbaril e $H$. oblongifolia (LANGENHEIM; LEE, 1974), indicando ser comum em espécies desses gêneros. Não foram encontrados estudos referentes ao padrão de nervação das folhas jovens de espécies do gênero Copaifera para comparação com os obtidos em G. hymenifolia. Apesar de a morfologia foliar ser diferente entre esses gêneros, estudos comparativos do padrão de nervação são fundamentais para diferenciação das plântulas e plantas jovens dessas espécies em ambiente natural.

\section{CONCLUSÕES}

Os resultados deste estudo evidenciaram a existência de semelhanças morfológicas entre os frutos e sementes de G. hymenifolia e C. langsdorffii; entretanto, a morfologia foliar diferiu entre essas espécies. Por outro lado, plântulas e plantas jovens de $G$. hymenifolia mostraram morfologia foliar e padrão de nervação semelhante ao gênero Hymenaea. Tais resultados contribuíram para a caracterização biológica de G. hymenifolia e auxiliaram na identificação das formas juvenis em ambiente natural.

\section{AGRADECIMENTOS}

À Universidade Estadual de Mato Grosso do Sul (UEMS), Unidade de Ensino de Jardim, por ceder laboratório e viveiro de mudas para realização deste estudo; à bióloga Eliete da Silva Cardoso, pela ajuda nos trabalhos de laboratório; e à Sra. Elizabete Secomandi, por autorizar a coleta de material botânico em sua propriedade, local denominado “Santuário do Prata”, em Jardim, MS.

\section{REFERÊNCIAS}

ALBRECHT, J. M. F. et al. Manual de produção de sementes de espécies florestais nativas. Cuiabá: Universidade Federal de Mato Grosso, 2003. 88p.

AMORIM, I. L. et al. Morfologia de frutos, sementes, plântulas e mudas de Senna multijuga var. lindleyana (Gardner) H. S. Irwin \& Barneby - Leguminosae Caesalpinioideae. Revista Brasileira de Botânica, v.31, n.3, p.507-516, 2008.
BARROSO, G. M. et al. Frutos e sementes. morfologia aplicada à sistemática de dicotiledôneas. Viçosa, MG: Universidade Federal de Viçosa, 1999. 443p.

BATTILANI, J. L.; SREMIN-DIAS, E.; SOUZA, A. L. T. Fitossociologia de um trecho da mata ciliar do rio da Prata, Jardim, MS, Brasil. Acta

Botanica Brasilica, v.19, n.3, p.597-608, 2005.

BATTILANI, J. L.; SANTIAGO, E. F.; SOUZA, A. L. T. Morfologia de frutos, sementes e desenvolvimento de plântulas e plantas jovens de Maclura tinctoria (L.) D. Don. ex Steud.

(Moraceae). Acta Botanica Brasilica, v.20, n.3, p.581-589, 2006.

BATTILANI, J. L.; SANTIAGO, E. F.; SOUZA, A. L. T. Aspectos morfológicos de frutos, sementes e desenvolvimento de plântulas e plantas jovens de Unonopsis lindmanii Fries (Annonaceae). Acta Botanica Brasilica, v.21, n.4, p.897-907, 2007.

BARNEBY, R. C. Neotropical Fabales at NY: asides and oversights. Brittonia, v.48, p.174187, 1996.

BOTELHO, S. A. et al. Aspectos morfológicos de frutos, sementes, plântulas e mudas de jatobá-docerrado (Hymenaea stigonocarpa Mart. ex Hayne) - Fabaceae. Revista Brasileira de

Sementes, v.22, n.1, p.144-152, 2000.

CARDOSO, C. M. V.; SAJO, M. G. Vascularização foliar e identificação de espécies de Eugenia L. (Myrtaceae) da bacia hidrográfica do rio Tibagi, PR. Revista Brasileira de Botânica, v.27, n.1, p.47-54, 2004.

CORNER, E. J. H. The seeds of dicotyledons. Cambridge: University Press. v.I, 1976. 311p.

CRESTANA, C. M.; BELTRATI, C. M. Morfologia e anatomia das sementes de Copaifera langsdorffii Desf. (Leguminosae-Caesalpinioideae).

Naturalia, v.13, n.1, p.45-54, 1988.

CRUZ, E. D.; MARTINS, F. O.; CARVALHO, J. E. U. Biometria de frutos e sementes e germinação de jatobácuruba (Hymenaea intermedia Ducke, LeguminosaeCaesalpinioideae). Revista Brasileira de Botânica, v.24, n.2, p.161-166, 2001. 
CUNHA, M. C. L.; FERREIRA, R. A. Aspectos morfológicos da semente e do desenvolvimento da planta jovem de Amburana cearensis (Arr. Cam.) A.C. Smith - cumaru - Leguminosae Papilionoideae. Revista Brasileira de Sementes, v.25, n.2, p.89-96, 2003.

DAMASCENO JÚNIOR, G. A. Estudo florístico e fitossociológico de um gradiente altitudinal no maçiço urucum - Mato Grosso do Sul, Brasil. 164f. 2005. Tese (Doutorado em Biologia Vegetal) Universidade de Campinas, Campinas, 2005.

FERREIRA, R. A. et al. Morfologia de frutos, sementes, plântulas e plantas jovens de Dimorphandra mollis Benth.-faveira (LeguminosaeCaesalpiniodeae). Revista Brasileira de Botânica, v.24, n.3, p.303-309, 2001.

GUERRA, M. E. C.; MEDEIROS FILHO, S.; GALLÃO, M. I. Morfologia de sementes, de plântulas e da germinação de Copaifera Langsdorfii Desf. (Leguminosae-Caesalpinoideae). Cerne, v.12, n.4, p.322-328, 2006.

HANDRO, W. Contribuição ao estudo da venação e anatomia foliar das Amarantáceas dos cerrados. II - Gênero Pfaffia. Anais da Academia Brasileira de Ciências, v.39, n.3-4, p.495506, 1967.

HICKEY, L. J. A revised classification of the architecture of dicotyledonous leaves. In: METCALFE, C. L.; CHALK, R. (Eds). Anatomy of the dicotyledons. Systematic anatomy of leaf and stem, with a brief history of the subject. 2.ed. Oxford: Clarendon Press, 1979. v.1. p.25-40.

HOWE, H. F.; SMALLWOOD, J. Ecology of seed sispersal. Ecology Systematic, v.13, p.201228, 1982.

IBARRA MANRÍQUEZ, G.; RAMOS, M. M.; OYANA, K. Seedling functional types in a lowland rain forest in Mexico. American Journal of Botany, v.88, n.10, p.1801-1812, 2001.

JARDIM, A.; KILLEEN, T. J.; FUENTES, A. Guia de los arboles $y$ arbustos del Bosque Seco Chiquitano, Bolívia. St. Louis: Missouri Botanical Garden Press, 2003. 323p.
KODAMA, M. T.; SARTORI, A. L. B. Caracterização morfológica de plântulas de Hymenaea stigonocarpa var. stigonocarpa Mart. ex Hayne, $H$. stigonocarpa Hayne var. brevipetiolata N. Mattos e H. courbaril L. Revista Brasileira de Biociências, v.5, n.1, p.663-665, 2007.

LANGENHEIM, J. H.; LEE, Y. T. Reinstatement of the genus Hymenaea (Leguminosae:

Caesalpinioideae) in Africa. Brittonia, v.26, p.321, 1974.

LEONHARDT, C. et al. Morfologia e desenvolvimento de plântulas de 29 espécies arbóreas nativas da área da Bacia Hidrográfica do Guaíba, Rio Grande do Sul, Brasil. Iheringia Série Botânica, v.63, n.1, p.5-14, 2008.

LORENZI, H. Árvores brasileiras: manual de identificação e cultivo de plantas arbóreas nativas do Brasil. Nova Odessa: Plantarum, 1998. v.2. 351p.

MELO, M. G. G.; MENDONÇA, M. S.; MENDES, A. M. Análise morfológica de sementes, germinação e plântulas de jatobá (Hymenaea intermedia Ducke var. adenotricha (Ducke) Lee \& Lang.) Leguminosae-Caesalpinoideae. Acta Amazonica, v.34, n.1, p.9-14, 2004.

MELO, M. F. F.; VARELA, V. P. Aspectos morfológicos de frutos, sementes, germinação e plântulas de duas espécies florestais da amazônia. I. Dinizia excelsa Ducke (angelim pedra). II. Cedrelinga catenaeformis Ducke (cedrorana) Leguminosae: Mimosoideae. Revista Brasileira de Sementes, v.28, n.1, p.54-62, 2006.

MILANEZ, C. R. D.; OLIVEIRA, D. M. T.; MORAES DALLAQUA, M. A. Semi-hypogeal germination in Pachyrhizus ahipa (Wedd.) Parodi (Fabaceae: Phaseoleae): seedling and sapling morphology. Brazilian Archives of Biology and Technology, v.51, n.2, p.353-359, 2008.

OLIVEIRA, D. M. T. Análise morfológica comparativa de frutos, sementes, plântulas e plantas jovens de 30 espécies arbóreas de Fabaceae ocorrentes no Estado de São Paulo. 1997. 173f. Tese (Doutorado em Biologia Vegetal) - Universidade Estadual de São Paulo, Rio Claro, 1997. 173p.

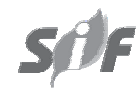

Revista Árvore, Viçosa-MG, v.35, n.5, p.1089-1098, 2011 
OLIVEIRA, D. M. T. Morfologia comparada de plântulas e plantas jovens de leguminosas em arbóreas nativas: espécies de Phaseoleae, Sophoreae, Swartzieae e Tephrosieae. Revista Brasileira de Botânica, v.24, n.1, p.85-97, 2001.

OLIVEIRA, D. A. et al. Potencial germinativo de sementes de fava-d'anta (Dimorphandra mollis Benth. - Fabaceae: Mimosoideae) sob diferentes procedências, datas de coleta e tratamentos de escarificação. Revista Árvore, v.32, n.6, p.1001-1009, 2008.

PAOLI, A. A. S; FREITAS, L.; BARBOSA, J. M. Caracterização morfológica dos frutos, sementes e plântulas de Croton floribundus Spreng. e de Croton urucurana Baill. (Euphorbiaceae).

Revista Brasileira de Sementes, v.17, n.1, p.57-68, 1995.

PINÃ-RODRIGUES, F. C. M. Guia prático para a colheita e manejo de sementes florestais tropicais. Rio de Janeiro: IDACO, 2002. 40p.

POTT, A.; POTT, V. J. Espécies de Fragmentos Florestais em Mato Grosso do Sul. In: COSTA, R.B. (Ed.). Fragmentação florestal e alternativas de desenvolvimento rural na Região Centro-Oeste. Campo Grande: Universidade Católica Dom Bosco, 2003. p.26-52.

RAMOS, M. B. P.; FERRAZ, I. D. K. Estudos morfológicos de frutos, sementes e plântulas de Enterolobium schomburgkii Benth. (LeguminosaeMimosoideae). Revista Brasileira de Botânica, v.31, n.2, p.227-235, 2008.

REYS, P. et al. Fenologia reprodutiva e disponibilidade de frutos de espécies arbóreas em mata ciliar no rio Formoso, Mato Grosso do Sul. Biota Neotropica, v.5, n.2, p.1-10, 2005.
RESSEL, K. et al. Ecologia morfofuncional de plântulas de espécies arbóreas da Estação Ecológica do Panga, Uberlândia, Minas Gerais. Revista Brasileira de Botânica, v.27, n.2, p.311-323, 2004.

ROTH, I. Fruits of angiosperms. Berlin: Gebrüder Borntraeger. Handbuch der Pflanzenanatomle, 1977.675p.

ROSSETO, J. et al. Germinação de sementes de Parkia pendula (Willd.) Benth. ex Walp. (Fabaceae) em diferentes temperaturas. Revista Árvore, v.33, n.1, p.47-55, 2009.

SANTIAGO, E. F.; PAOLI, A. A. S. Morfologia do fruto e da semente de Peltophorum dubium (Spreng.) Taubert (Leg-Caesalpinoideae). Naturalia, v.24, p.139-152, 1999.

SILVA, B. M. S.; MÔRO, F. V. Aspectos morfológicos do fruto, da semente e desenvolvimento pós-seminal de faveira (Clitoria fairchildiana R. A. Howard. Fabaceae). Revista Brasileira de Sementes, v.30, n.3, p.195-201, 2008.

TAKAHASHI, A.; FIANA, B. G. Síndromes de dispersão de sementes de uma área do Morro do Paxixi, Aquidauana, MS. In: SIMPÓSIO SOBRE RECURSOS NATURAIS E SÓCIO-ECONÔMICOS DO PANTANAL, 4., Corumbá, 2004. Anais... Corumbá: 2004.

VEIGA JÚNIOR, V. F. V.; PINTO, A. C. O gênero Copaifera L. Química Nova, v.25, n.2, p.273286, 2002.

WALLACE, R. B. et al. La estacionalidad y el manejo de vida silvestre en los bosques de producción del oriente de Bolívia. Boletim Ecology, v.8, p.65-81, 2000. 